\title{
The Relationship Between Sexually Dimorphic Peripheral Nerves and Diseases
}

\author{
Hiroshi Moriyama
}

Additional information is available at the end of the chapter

http://dx.doi.org/10.5772/56080

\section{Introduction}

With regard to the incidence of peripheral nerve diseases and peripheral nerve damage after surgical procedures, there are reports of sexual dimorphism, no sexual dimorphism, and little sexual dimorphism. However, details of the morphology and sexual dimorphism in the characteristics of peripheral nerves have not been available in textbooks. I morphometrically analyzed peripheral nerves and clarified these issues.

\section{Materials and methods}

The materials used in this study were Japanese oculomotor nerves, ophthalmic nerves, inferior alveolar nerves, abducent nerves, facial nerves, vestibular nerves, cochlear nerves, and vagus nerves, recurrent laryngeal nerves in the cranial nerve group; Japanese femoral nerves and tibial nerves in the spinal nerve group; and Japanese greater splanchnic nerves and lesser splanchnic nerves in the autonomic nerve group. All the cadavers were donated with the individual's consent. We proceeded to perform this research in accordance with the law concerning autopsy and preservation of corpses, and concerning donation for medical and dental education. In no case was there a history of peripheral nerve disorders such as neuroparalysis or schwannoma, or of treatment with toxic agents or irradiation therapy. The causes of death did not directly or indirectly influence the nervous system, so the peripheral nerves were considered to be normal. I used right side specimens of right-handed persons to avoid any interaction between the effects of sex and side. Moreover, the age of specimens showed no significant difference between female and male specimens. The data on the above pairs of groups were thus independent of the aging process. The methods for preparation of sections, also described in our previous report [1], were as follows: 


\subsection{Fixation}

The fixation involved a two-step process. For the first step, all the cadavers were fixed with a $10 \%$ solution of formalin ( $3.7 \%$ formaldehyde) within $24 \mathrm{~h}$ postmortem. After resecting the peripheral nerves, a $10 \%$ solution of formalin (3.7\% formaldehyde) was used for immersion for at least a week. The solution was changed once in the first 30-60 min and again, later if desired.

The formalin-fixed materials were then transferred without washing to the secondary fixative (1:4 mixture of $5 \% \mathrm{~K}_{2} \mathrm{Cr}_{2} \mathrm{O}_{7}$ and $5 \% \mathrm{~K}_{2} \mathrm{CrO}_{4}$ ) and maintained at room temperature for 2 weeks. If the solution became turbid or precipitated it was changed. After this, the fixation was continued at $37^{\circ} \mathrm{C}$ for an additional week. The volume of fixative used was at least ten times the volume of the specimens.

\subsection{Washing}

The fixed materials were washed in running water for around $24 \mathrm{~h}$. We used a siphonoperated automatic pipette washer with the materials packed in a small plastic basket.

\subsection{Dehydration and celloidin embedding}

1. $50 \%$ ethanol, for several days

2. $70 \%$ ethanol, for several days

The alcohol in steps 1 and 2 was changed if it became yellow.

3. $90 \%$ ethanol, overnight

4. $95 \%$ ethanol, overnight

5. Pure ethanol, one night or more

6. Ether/ethanol, 1:1 overnight

7. $1 \%$ celloidin in ether/ethanol, several days

8. $7 \%$ celloidin, several days

9. $14 \%$ celloidin for embedding, several weeks

10. Immerse hardened celloidin embedded blocks in $90-95 \%$ ethanol for several hours

11. Maintained celloidin blocks in $70 \%$ ethanol prior to sectioning

\subsection{Staining procedures}

Modified luxol fast blue-periodic acid Schiff-hematoxylin (LPH) triple stain.

1. Cut sections $15 \mu \mathrm{m}$ thick and place in $90 \%$ ethanol

2. Rinse sections in $95 \%$ ethanol

3. Keep at $58^{\circ} \mathrm{C}$ overnight in LFB solution $(0.1 \%$ solution of luxol fast blue by dissolving $1.0 \mathrm{~g}$ of the substance in 1,000 $\mathrm{ml}$ of $95 \%$ ethanol) placed in a shallow sealed jar.

4. Immerse in $95 \%$ ethanol and wash off excess stain

5. Wash in distilled water 
6. Differentiate in $2 \%$ saturated lithium carbonate $\left(=0.03 \% \mathrm{Li}_{2} \mathrm{CO}_{3}\right)$ for $60 \mathrm{~min}$

7. Continue differentiation with one or two changes of $70 \%$ ethanol until myelin sheaths can be distinguished. If necessary, repeat steps 5 through 7 until there is sharp contrast between myelin sheaths and surrounding structures.

8. Finish differentiation by rinsing in $95 \%$ ethanol

9. Wash in distilled water (two changes)

10. Oxidize for $5 \mathrm{~min}$ in $0.5 \%$ periodic acid

11. Wash in distilled water (several changes)

12. Immerse for $15 \mathrm{~min}$ in Schiff's reagent

13. Immediately transfer to $5 \%$ sodium hydrogen sulfite and leave for about $5 \mathrm{~min}$, changing the solution three times

14. Wash in distilled water (several changes)

15. Immerse sections for around 5 min in Mayer's hematoxylin solution

16. Wash sections in distilled water (several changes) until sections turn bluish.

17. Rinse in $90-95 \%$ ethanol

18. Dehydrate sections in $n$-butyl alcohol (three changes)

19. Clear sections in xylene (three changes)

20. Mount in balsam

\subsection{Morphometry}

I observed the fascicles at low power (Fig. 1). I covered the entire area of the distributed myelinated axons in the peripheral nerve by moving the eyepiece grid vertically and horizontally. I confirmed that I could distinguish myelinated structures from vessels in the tissue with a computer or grouped unmyelinated axons with the naked eye in each grid. I counted the myelinated axons and measured the transverse area and perimeter of the myelinated axons in a square eyepiece grid at high power (Fig. 2). To avoid duplicate counts, I counted and measured all axons on the side of the grid that did not come into contact with the other grids. In the case of grids adjacent to the other grids, I counted and measured only the axons on the lower right side of the grid, not those on the upper left side. I used a microscope in transmitted light mode (BX50, Olympus, Tokyo, Japan) equipped with a high-resolution digital camera (ColorView12, Soft Imaging System, Münster, Germany), a motorized XYZ stage (Märzhäuser, Wetzlar-Steindorf, Germany), a stage controller (Märzhäuser, Wetzlar-Steindorf, Germany), and a computer (Precision 530, Dell, Austin, TX, USA) with analyzing system software (analySIS 3.0, Soft Imaging System, Münster, Germany) to store data on-line, do calculations, and perform statistical analyses. Circularity ratios $(\mathrm{CR})$ were calculated as follows: $\mathrm{CR}=4 \pi \mathrm{A} / \mathrm{L}^{2}\left(\mathrm{~A}=\right.$ area in $\mathrm{mm}^{2} ; \mathrm{L}=$ perimeter in $\mathrm{mm}$ ).

If a circle is regular, the ratio has a maximum value of 1.0, and if it is irregular, the value is less than 1. This indicates how near or far each irregularity is from a regular round figure, allowing quantitative comparison of round figures. 


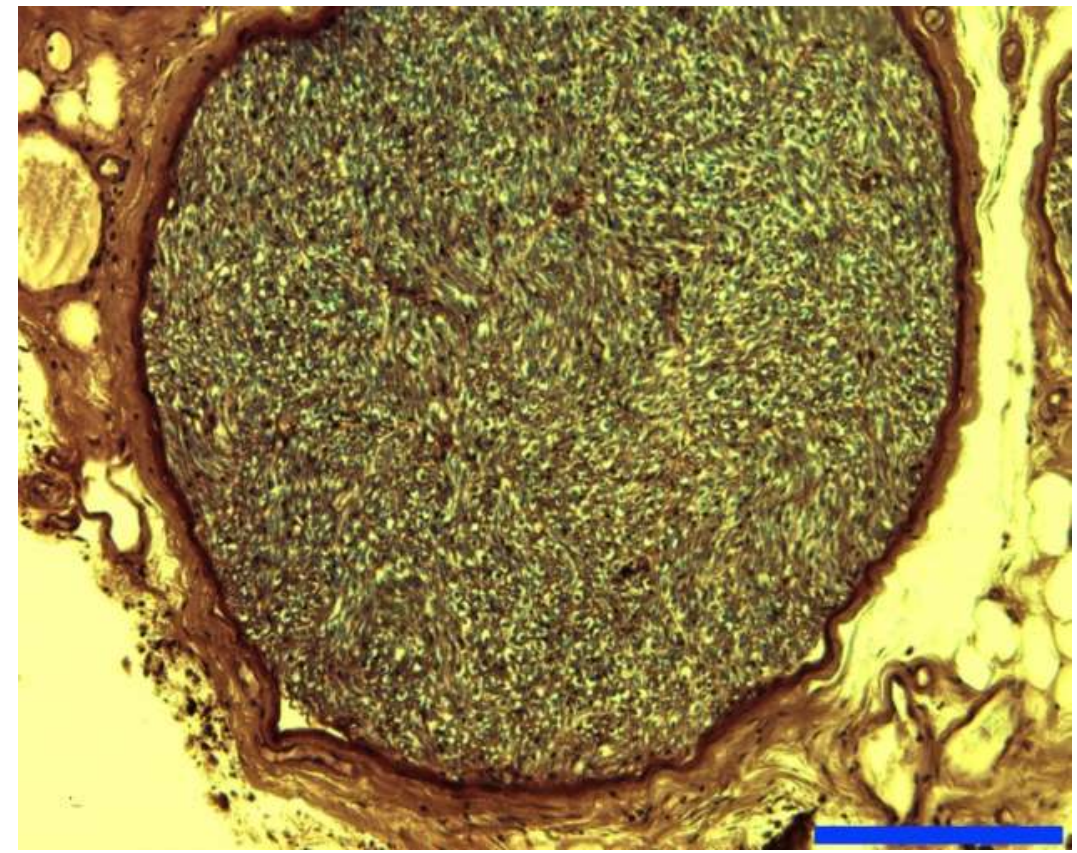

Figure 1. A low-power view of the inferior alveolar nerve from a 65-year-old woman, modified LPH stain. Scale bar $200 \mu \mathrm{m}$

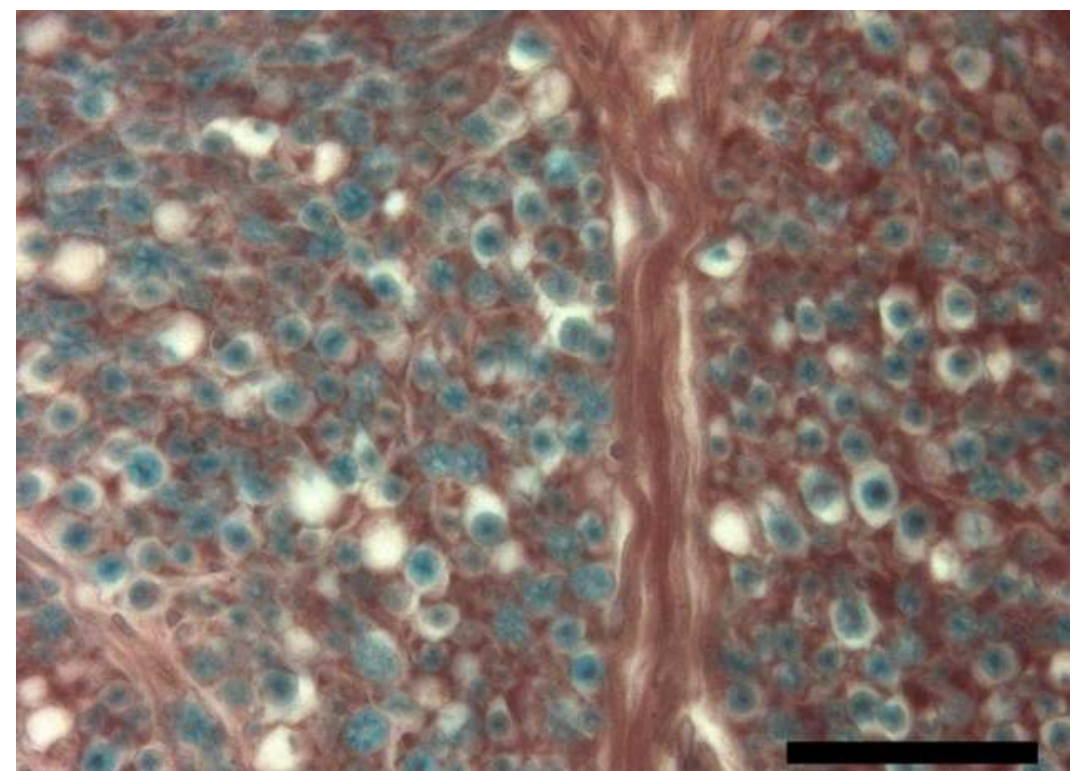

Figure 2. A high-power view of the facial nerve from a 44-year-old woman, modified LPH stain. Axons were stained dark purple or black, and surrounded by a myelin sheath stained deep green. Scale bar $50 \mu \mathrm{m}$ 


\subsection{Statistical analyses}

All statistical analyses were performed using JMP statistical software version 9.0.3 (SAS Institute Inc. Cary, NC, USA) on a Macintosh personal computer.

Researchers have studied shrinkage of embedding materials, and found that celloidin and plastination embedding exhibit less shrinkage (around 10\%) than paraffin and other embeddings [2]. Therefore, although I measured every myelinated axon, I calculated the average transverse area and perimeter of myelinated axons after excluding data far from the median $(15 \%)$ due to shrinkage.

Morphological differences between female and male specimens were analyzed by applying a parametric unpaired $t$ test (where data were normally distributed with equal variance) to the total number of myelinated axons and the average transverse area, perimeter and CR. A $p$ value of $<0.05$ was considered to indicate a statistically significant difference.

\section{Results}

\subsection{Number of myelinated axons}

We estimated the total number or number per unit area of myelinated axons (NM) in the peripheral nerves (Table 1). The myelinated nerve fibers appeared as a blue-green myelin sheath surrounding a dark purple or black axon (Fig. 2). According to the data, there was no statistically significant difference in the total number of myelinated axons between the female and male specimens of the peripheral nerves, except for the vestibular nerve $(P<$ 0.05; Table 1).

\subsection{Average transverse area of myelinated axons}

The average transverse area of myelinated axons (ATA) in the peripheral nerves was calculated (Table 1). According to the data, there was no statistically significant difference in the average transverse area of myelinated axons between the female and male specimens of all calculated peripheral nerves $(P<0.05$; Table 1$)$.

\subsection{CR of myelinated axons}

The average CR of myelinated axons (ACR) in the peripheral nerves was calculated (Table 1) and there was no statistically significant difference in the average CR of myelinated axons between the female and male specimens of the peripheral nerves, except for the vagus nerve $(P<0.05 ;$ Table 1$)$.

\section{Discussion}

Researchers have reported that a decrease in the number and size of myelinated axons influences the occurrence of peripheral nerve palsy or neuropathy [3-6], and a lower CR of myelinated axons has been partly implicated in the degeneration of nerve fibers [7]. A 
smaller NM, ATA, and lower ACR of myelinated axons would help explain the sex difference in the incidence of peripheral nerve palsy and neuropathy.

\begin{tabular}{|c|c|c|c|c|c|c|c|}
\hline Nerve & Side & Sex & $\begin{array}{l}\text { Number of } \\
\text { Specimens }\end{array}$ & Age & $\begin{array}{l}\text { Total Number or } \\
\text { Number/Unit area }\end{array}$ & $\begin{array}{c}\text { Average } \\
\text { Transverse Area } \\
\left(\mu \mathrm{m}^{2}\right)\end{array}$ & $\begin{array}{c}\text { Average } \\
\text { Circularity Ratio }\end{array}$ \\
\hline \multirow{4}{*}{ Oculomotor } & $\mathrm{R}$ & $\mathrm{F}$ & 10 & $70.8 \pm 8.6$ & $18,905 \pm 4,861$ & $5.59 \pm 1.54$ & $0.83 \pm 0.07$ \\
\hline & $\mathrm{R}$ & M & 10 & $72.5 \pm 8.9$ & $18,523 \pm 5,700$ & $6.28 \pm 1.95$ & $0.83 \pm 0.06$ \\
\hline & & $p$ value & & $\mathrm{P}=0.65$ & $\mathrm{P}=0.79$ & $\mathrm{P}=0.62$ & $\mathrm{P}=0.82$ \\
\hline & & $95 \% \mathrm{CI}$ & & -6.5 to 9.9 & $-5,359$ to 4,595 & -0.97 to 2.34 & -0.06 to 0.06 \\
\hline \multirow[t]{4}{*}{ Ophthalmic } & $\mathrm{R}$ & $\mathrm{F}$ & 22 & $75.2 \pm 13.8$ & $34 \pm 11 / 16 \times 16 \mu \mathrm{m}^{2}$ & $4.86 \pm 2.27$ & $0.83 \pm 0.05$ \\
\hline & $\mathrm{R}$ & M & 22 & $73.3 \pm 15.7$ & $36 \pm 7 / 16 \times 16 \mu \mathrm{m}^{2}$ & $4.88 \pm 1.38$ & $0.84 \pm 0.06$ \\
\hline & & $\mathrm{p}$ value & & $\mathrm{P}=0.82$ & $\mathrm{P}=0.47$ & $\mathrm{P}=0.94$ & $\mathrm{P}=0.65$ \\
\hline & & $95 \% \mathrm{CI}$ & & -15.8 to 12.0 & -7 to 11 & -1.75 to 1.79 & -0.04 to 0.07 \\
\hline \multirow[t]{4}{*}{$\begin{array}{l}\text { Inferior } \\
\text { Alveolar }\end{array}$} & $\mathrm{R}$ & F & 11 & $72.5 \pm 8.6$ & $21,885 \pm 7,711$ & $34.90 \pm 8.97$ & $0.87 \pm 0.03$ \\
\hline & $\mathrm{R}$ & M & 11 & $75.6 \pm 7.3$ & $23,623 \pm 6,684$ & $30.95 \pm 8.76$ & $0.86 \pm 0.05$ \\
\hline & & $\mathrm{p}$ value & & $\mathrm{P}=0.32$ & $\mathrm{P}=0.55$ & $\mathrm{P}=0.62$ & $\mathrm{P}=0.77$ \\
\hline & & $95 \% \mathrm{CI}$ & & -4.0 to 10.2 & $-4,680$ to 8,157 & -11.84 to 3.93 & -0.05 to 0.03 \\
\hline \multirow[t]{4}{*}{ Abducent } & $\mathrm{R}$ & $\mathrm{F}$ & 10 & $73.8 \pm 7.4$ & $1,854 \pm 343$ & $4.34 \pm 0.75$ & $0.80 \pm 0.08$ \\
\hline & $\mathrm{R}$ & M & 10 & $75.6 \pm 9.3$ & $2,139 \pm 502$ & $3.46 \pm 0.50$ & $0.76 \pm 0.06$ \\
\hline & & $\mathrm{p}$ value & & $\mathrm{P}=0.68$ & $\mathrm{P}=0.40$ & $\mathrm{P}=0.09$ & $\mathrm{P}=0.75$ \\
\hline & & $95 \% \mathrm{CI}$ & & -10.5 to $14 . \quad 1$ & -341 to 911 & -1.81 to 0.05 & -0.14 to 0.07 \\
\hline \multirow[t]{4}{*}{ Facial } & $\mathrm{R}$ & $\mathrm{F}$ & 10 & $65.9 \pm 15.9$ & $6,023 \pm 955$ & $6.34 \pm 0.92$ & $0.80 \pm 0.04$ \\
\hline & $\mathrm{R}$ & M & 10 & $65.1 \pm 15.2$ & $6,466 \pm 735$ & $6.27 \pm 0.74$ & $0.79 \pm 0.03$ \\
\hline & & $\mathrm{p}$ value & & $\mathrm{P}=0.91$ & $\mathrm{P}=0.26$ & $\mathrm{P}=0.86$ & $\mathrm{P}=0.85$ \\
\hline & & $95 \% \mathrm{CI}$ & & -13.8 to 15.4 & -357 to 1,244 & -0.71 to 0.85 & -0.13 to 0.10 \\
\hline \multirow[t]{4}{*}{ Vestibular } & $R$ & $\mathrm{~F}$ & 12 & $75.4 \pm 9.6$ & $18,022 \pm 2,780$ * & $3.76 \pm 0.65$ & $0.88 \pm 0.03$ \\
\hline & $\mathrm{R}$ & M & 12 & $74.2 \pm 10.2$ & $21,002 \pm 4,636$ * & $3.56 \pm 0.93$ & $0.86 \pm 0.08$ \\
\hline & & $\mathrm{p}$ value & & $P=0.69$ & $\mathrm{P}=0.04$ & $\mathrm{P}=0.56$ & $\mathrm{P}=0.93$ \\
\hline & & $95 \% \mathrm{CI}$ & & -9.7 to 7.2 & -256 to 6,217 & -0.88 to 0.48 & -0.07 to 0.03 \\
\hline \multirow[t]{4}{*}{ Cochlear } & $\mathrm{R}$ & $\mathrm{F}$ & 12 & $68.7 \pm 18.0$ & $23,597 \pm 5,377$ & $1.81 \pm 0.40$ & $0.86 \pm 0.01$ \\
\hline & $\mathrm{R}$ & M & 12 & $72.0 \pm 17.9$ & $26,598 \pm 6,177$ & $1.78 \pm 0.30$ & $0.86 \pm 0.02$ \\
\hline & & $\mathrm{p}$ value & & $\mathrm{P}=0.75$ & $\mathrm{P}=0.30$ & $\mathrm{P}=0.69$ & $\mathrm{P}=0.62$ \\
\hline & & $95 \% \mathrm{CI}$ & & -19.7 to 26.4 & $-4,449$ to 10,450 & -0.48 to 0.43 & -0.02 to 0.01 \\
\hline \multirow[t]{4}{*}{ Vagus } & $\mathrm{R}$ & $\mathrm{F}$ & 15 & $75.9 \pm 15.4$ & $1,413 \pm 274$ & $1.12 \pm 0.33$ & $0.79 \pm 0.06^{*}$ \\
\hline & $\mathrm{R}$ & M & 15 & $77.8 \pm 11.2$ & $1,331 \pm 192$ & $1.21 \pm 0.30$ & $0.83 \pm 0.06 *$ \\
\hline & & $p$ value & & $\mathrm{P}=0.79$ & $\mathrm{P}=0.72$ & $\mathrm{P}=0.57$ & $\mathrm{P}=0.03$ \\
\hline & & $95 \% \mathrm{CI}$ & & -8.1 to 11.9 & -257 to 94 & -0.15 to 0.32 & -0.00 to 0.09 \\
\hline \multirow[t]{4}{*}{$\begin{array}{l}\text { Recurrent } \\
\text { Laryngeal }\end{array}$} & $\mathrm{R}$ & F & 10 & $78.7 \pm 10.2$ & $14 \pm 2 / 33 \times 33 \mu \mathrm{m}^{2}$ & $10.06 \pm 3.15$ & $0.88 \pm 0.04$ \\
\hline & $\mathrm{R}$ & M & 10 & $73.0 \pm 8.8$ & $14 \pm 3 / 33 \times 33 \mu \mathrm{m}^{2}$ & $10.38 \pm 2.57$ & $0.89 \pm 0.06$ \\
\hline & & $\mathrm{p}$ value & & $\mathrm{P}=0.28$ & $\mathrm{P}=0.96$ & $\mathrm{P}=0.96$ & $\mathrm{P}=0.51$ \\
\hline & & $95 \% \mathrm{CI}$ & & -15.5 to 5.3 & -3 to 3 & -2.77 to 3.41 & -0.05 to 0.08 \\
\hline \multirow[t]{4}{*}{ Femoral } & $R$ & $\mathrm{~F}$ & 10 & $83.7 \pm 9.9$ & $26.7 \pm 11.7$ & $5.06 \pm 1.54$ & $0.93 \pm 0.08$ \\
\hline & $\mathrm{R}$ & M & 10 & $76.4 \pm 11.8$ & $30.4 \pm 10.9$ & $6.09 \pm 1.84$ & $0.92 \pm 0.07$ \\
\hline & & $\mathrm{p}$ value & & $\mathrm{P}=0.31$ & $\mathrm{P}=0.52$ & $\mathrm{P}=0.31$ & $\mathrm{P}=0.70$ \\
\hline & & $95 \% \mathrm{CI}$ & & -20.0 to 5.4 & -9.5 to 16.9 & -0.94 to 3.01 & -0.09 to 0.07 \\
\hline \multirow[t]{4}{*}{ Tibial } & $\mathrm{R}$ & $\mathrm{F}$ & 10 & $84.9 \pm 12.3$ & $1,023 \pm 680$ & $2.60 \pm 0.39$ & $0.94 \pm 0.05$ \\
\hline & $\mathrm{R}$ & M & 10 & $82.5 \pm 9.9$ & $1,491 \pm 1,061$ & $3.20 \pm 0.75$ & $0.90 \pm 0.09$ \\
\hline & & $p$ value & & $\mathrm{P}=0.61$ & $\mathrm{P}=0.72$ & $\mathrm{P}=0.07$ & $\mathrm{P}=0.57$ \\
\hline & & $95 \% \mathrm{CI}$ & & -16.2 to 11.5 & -602 to 1,538 & -0.11 to 1.31 & -0.12 to 0.05 \\
\hline
\end{tabular}




\begin{tabular}{|c|c|c|c|c|c|c|c|}
\hline Nerve & Side & Sex & $\begin{array}{l}\text { Number of } \\
\text { Specimens }\end{array}$ & Age & $\begin{array}{l}\text { Total Number or } \\
\text { Number/Unit area }\end{array}$ & $\begin{array}{c}\text { Average } \\
\text { Transverse Area } \\
\left(\mu \mathrm{m}^{2}\right)\end{array}$ & $\begin{array}{c}\text { Average } \\
\text { Circularity Ratio }\end{array}$ \\
\hline \multirow[t]{2}{*}{$\begin{array}{c}\text { Greater } \\
\text { Splanchnic }\end{array}$} & $\mathrm{R}$ & F & 15 & $73.3 \pm 15.6$ & $8 \pm 2 / 16 \times 16 \mu \mathrm{m}^{2}$ & $5.18 \pm 1.36$ & $0.88 \pm 0.07$ \\
\hline & $\mathrm{R}$ & $\begin{array}{c}\mathrm{M} \\
\text { p value } \\
95 \% \mathrm{CI} \\
\end{array}$ & 15 & $\begin{array}{c}72.9 \pm 12.1 \\
P=0.93 \\
-10.8 \text { to } 10.0\end{array}$ & $\begin{array}{c}9 \pm 2 / 16 \times 16 \mu \mathrm{m}^{2} \\
\mathrm{P}=0.43 \\
-1 \text { to } 2\end{array}$ & $\begin{array}{c}5.54 \pm 1.26 \\
P=0.35 \\
-0.62 \text { to } 1.33\end{array}$ & $\begin{array}{c}0.87 \pm 0.06 \\
\mathrm{P}=0.71 \\
-0.06 \text { to } 0.04\end{array}$ \\
\hline \multirow[t]{2}{*}{$\begin{array}{c}\text { Lesser } \\
\text { Splanchnic }\end{array}$} & $\mathrm{R}$ & F & 15 & $73.7 \pm 15.5$ & $12 \pm 6 / 16 \times 16 \mu \mathrm{m}^{2}$ & $1.63 \pm 0.96$ & $0.85 \pm 0.10$ \\
\hline & $\mathrm{R}$ & $\begin{array}{c}\mathrm{M} \\
\text { p value } \\
95 \% \mathrm{CI}\end{array}$ & 15 & $\begin{array}{c}72.1 \pm 12.5 \\
P=0.66 \\
-12.3 \text { to } 9.1\end{array}$ & $\begin{array}{c}14 \pm 7 / 16 \times 16 \mu \mathrm{m}^{2} \\
\mathrm{P}=0.43 \\
-3 \text { to } 8\end{array}$ & $\begin{array}{c}1.55 \pm 0.62 \\
\mathrm{P}=0.88 \\
-0.67 \text { to } 0.52\end{array}$ & $\begin{array}{c}0.86 \pm 0.11 \\
\mathrm{P}=0.96 \\
-0.08 \text { to } 0.10\end{array}$ \\
\hline
\end{tabular}

Table 1. Nerve fiber analysis of peripheral nerves in humans.

\subsection{Oculomotor nerve}

Cabrejas et al. reported epidemiological data on oculomotor nerve palsy that there were $59.1 \%$ males, with no statistically significant difference between females and males $(\mathrm{p}=$ 0.574) [8]. Moreover, Ohguro et al. reported finding differences in oculomotor nerve palsy with causative disease incidence according to sex, but they reported finding no significant difference in oculomotor nerve palsy with unknown cause incidence according to sex [9]. According to the data in this study, there was no statistically significant difference in the NM, ATA, or ACR of myelinated axons between the female and male specimens of the oculomotor nerve $(P<0.05$; Table 1$)$. My findings may partly explain why there is no significant sex difference in the incidence of oculomotor nerve palsy.

\subsection{Ophthalmic nerve}

Researchers have reported that the incidence rate of trigeminal neuralgia (TN) was slightly higher for females than for males. For example, the female-to-male ratio was 1.74:1 in the Katusic et al. study [10] and 3:2 in another study by Ashkenazi and Levin [11]. It has been proposed that the symptoms of $\mathrm{TN}$ are caused by demyelination of the nerve leading to ephaptic transmission of impulses. Surgical specimens have demonstrated this demyelination and close apposition of demyelinated axons in the trigeminal root of patients with TN [12]. Results from experimental studies suggest that demyelinated axons are prone to ectopic impulses, which may transfer from light touch to pain fibers in close proximity (ephaptic conduction) [12]. Current theories regarding the cause of this demyelination center on vascular compression of the nerve root by aberrant or tortuous vessels. Accepting current theories, neurovascular (or microvascular) decompression, when a pad is placed between a vessel and the nerve, has been found empirically to be an effective treatment for TN in cases resistant to medical therapy, and as many as $90 \%$ of cases have been relieved [13-15]. Barker et al. reported that 706 patients (around 60\%) were female of 1185 patients 
who underwent microvascular decompression, and female sex was a risk factor for recurrence after microvascular decompression (hazard ratio 1.3; $P=0.06$ ) [16]. According to the data here, there was no statistically significant difference in the NM, ATA, or ACR of myelinated axons between the female and male specimens of the ophthalmic nerve $(P<0.05$; Table 1). Therefore, a vascular abnormality in the female TN may be one reason why TN has a female preponderance, but morphology in the characteristic nerve does not appear to explain the sex difference in the incidence of TN.

\subsection{Inferior alveolar nerve}

Inferior alveolar nerve (IAN) damage can occur after an IAN block [17, 18] or following oral and maxillofacial surgical procedures [19-24]. With regard to the incidence of IAN damage after these procedures, Haas and Lennon reported no significant sex difference (ratio of affected females to males, 72:68) [25]. Kipp et al. also reported that the incidence was 7\% in both sexes, indicating no significant sex difference [26], while Harn and Durham reported that there was little sex difference in postinjection lingual nerve injuries (ratio of affected females to males, 24:17) [27]. Meanwhile, sexual dimorphism that results in the incidence being almost twice as high in females than in males has been reported [17, 28, 29]. Pogrel and Thamby [17] found the difference in referral rates for male and female patients difficult to explain. They mentioned that there have been studies suggesting that nerves respond differently to injury in female animals than in male animals [30]. Coyle et al. [31] reported that female rats were more prone to developing tactile allodynia than male rats after partial sciatic nerve ligation. These reports [30, 31] may partially explain the indicated sex difference in the incidence of IAN damage. According to this study's data, there was no statistically significant difference in the NM, ATA, or ACR of myelinated axons between the female and male IAN specimens $(P<0.05$; Table 1$)$. Heasman and Beynon [32] reported a difference between the total number of myelinated axons in the human IAN of dentate and edentulous groups as significant $(\mathrm{P}<0.001)$ and suggested axonal atrophy in the main nerve trunk following tooth loss. As each cadaver in this study had 7 teeth (central incisor, lateral incisor, canine, first premolar, second premolar, first molar, and second molar) on the side of the mandible that I used, I considered that this result was not affected by the dentulous condition. Therefore, the results of this study suggest a nonsignificant sex difference in the incidence of IAN damage, supported by the morphometric analysis. These findings may partly explain why there is no significant sex difference in the incidence of IAN damage.

\subsection{Abducent nerve}

Patel et al. reported 69 male (50\%) and 68 female (50\%) cases of abducent nerve palsy or paresis [33]. According to this study, ATA in the female abducent nerve was larger than that in the male abducent nerve, but there was no statistically significant difference in the NM, ATA, or ACR of myelinated axons between the female and male specimens of the oculomotor nerve $(P<0.05$; Table 1$)$. My findings may partly explain why there is no significant sex difference in the incidence of abducent nerve palsy or paresis. 


\subsection{Facial nerve}

Campbell and Brundage [34] reported that the incidence rate of Bell's palsy (BP) was slightly higher for females than for males (rate ratio $=1.16$ ). Meanwhile, Monini et al. [35] reported that males were slightly more affected (53.7\%) than females. However, many researchers have reported finding no significant difference in BP incidence according to sex, as Tiemstra and Khatkhate [36] recently reported. In this study, there was no statistically significant difference in the NM, ATA, or ACR of myelinated axons between the female and male facial nerve specimens $(P<0.05$; Table 1$)$. These findings may partly explain why there is no significant sex difference in the incidence of BP.

\subsection{Vestibular nerve}

The incidence of vestibular dysfunction has a female preponderance in a textbook description [37]. There was a marked female preponderance among individuals with vestibular vertigo (one year prevalence ratio female to male of 2.7:1.0) [38]. Neuhauser et al. also reported that prevalence and incidence rates of vestibular vertigo were consistently higher in females than in males, for example, the lifetime prevalence ratio of female to male was 10.3:4.3, and the population incidence ratio (one year) female to male was 1.9:0.8 [39]. This female preponderance tended to increase with age [40]. Yin et al. reported that adults (18-65y) had a ratio of affected females to males of 59.1:40.9, but elderly adults ( $>65 \mathrm{y})$ had a ratio of 60.6:39.4 [40]. With regard to Menière's disease, a female preponderance can be assumed based on the data from Rochester (61\% women) [41] and is confirmed by the latest data from Finland [42]. The results here showed that NM was 2,980 (mean value) higher in the male vestibular nerve than the female vestibular nerve. My data also indicated a significant sex difference $(P=0.04$; Table 1$)$, but there was no statistically significant difference in the ATA and ACR of myelinated axons between the female and male vestibular nerve specimens $(P<0.05$; Table 1$)$. The lower NM of myelinated axons in the female vestibular nerve may be one of the reasons why vestibular disorders have a female preponderance, but the findings here on ATA and ACR of myelinated axons did not appear to explain the sex difference in the incidence of these diseases.

\subsection{Cochlear nerve}

There are some reports regarding the incidence of cochlear dysfunction with sex difference. The incidence of tinnitus has a female preponderance in a textbook description [43]. Meanwhile, Graham [44] and the National Study of Hearing [45] reported that the incidence rate of tinnitus was higher for females than for males until the mid-fifties, but after the midfifties, that of tinnitus was higher for males than for females. Møller et al. reported that of the 72 patients who underwent microvascular decompression of the intracranial portion of the auditory nerve, $54.8 \%$ experienced total relief from tinnitus or marked improvement [46]. This report indicated that vascular compression of the auditory nerve was a factor in tinnitus. Therefore, vascular abnormalities in tinnitus patients may be one reason why tinnitus shows a sex difference, but morphology in the characteristic nerve does not appear 
to explain the sex difference in the incidence of tinnitus. Next, with regard to the incidence of hearing acuity, Kacker reported that there was no significant sex difference [47]. Meanwhile, Hinchcliffe and Jones reported that the hearing acuity in males was better than that in females [48]. Researchers also reported that the differences in hearing levels between females and males depended on the frequencies or race [49, 50]. Moreover, Star et al. reported that there were four females and six males among 10 patients with auditory nerve disease [51]. The main lesion in auditory nerve disease is thought to be demyelination or degeneration of cochlear nerve fibers. Finally, Nakashima examined the nationwide epidemiological study of sudden deafness in 1993, and reported that there was no significant sex difference [52]. In this study, there was no statistically significant difference in the NM, ATA, or ACR of myelinated axons between the female and male cochlear nerve specimens $(P<0.05$; Table 1$)$. The findings here may partly explain why there is no significant sex difference in the incidence of cochlear dysfunction.

\subsection{Vagus nerve}

Araújo et al. assessed vagal activity using heart rate response to a short (4s) bicycle exercise test during maximal inspiratory apnea. This study aimed to evaluate the role of sex and physical activity patterns on vagal activity. As a result, no sex effect could be identified [53]. With regard to vagoglossopharyngeal neuralgia, researchers reported that there was no preponderance regarding sex [54,55]. I gave a supplementary explanation for the term "vagoglossopharyngeal neuralgia". As researchers took the central or peripheral overlap between the glossopharyngeal nerve and vagus nerve into consideration, they grouped glossopharyngeal and vagal neuralgia together, and used the more useful vagoglossopharyngeal neuralgia in clinical practice [56, 57]. Meanwhile, Khasar et al. reported that under normal conditions, responses to noxious stimuli were modulated by vagus nerve activity in males, but not in females [58]. My results showed that ACR was 0.04 (mean value) higher in the male vagus nerve than the female vagus nerve. My data also indicated a significant sex difference $(P=0.03$; Table 1$)$. However, there was no statistically significant difference in the NM and ATA of myelinated axons between the female and male vagus nerve specimens $(P<0.05$; Table 1$)$. The higher ACR of myelinated axons in the male vagus nerve may be one reason why vagus nerve activity to modulate pain has a male preponderance. My findings regarding the NM and ATA of myelinated axons may partly explain why there is no significant sex difference in the incidence of vagoglossopharyngeal neuralgia.

\subsection{Recurrent laryngeal nerve}

With respect to sex, males with recurrent laryngeal nerve paralysis were more frequent than females in some reports [59-65] whereas in some other reports [66-68], there were more females than males with that condition. However, overall the above data indicated that there were 1,526 females with recurrent laryngeal nerve paralysis (48.5\%) and 1,618 males $(51.5 \%)$ [64]. Therefore, there was no significant difference in the number of patients 
between the two sexes. In this study, there was no statistically significant difference in the NM, ATA, or ACR of myelinated axons between the female and male recurrent laryngeal nerve specimens $(P<0.05$; Table 1$)$. These findings may partly explain why there is no significant sex difference in the incidence of recurrent laryngeal nerve paralysis.

\subsection{Femoral and tibial nerve}

Shinoda analyzed data on adult motor neuropathy in past reports, and mentioned that the vulnerability of male motor neurons was higher than that of female motor neurons [69]. With regard to amyotrophic lateral sclerosis (ALS), a progressive disorder of motor neurons, the incidence of ALS was slightly higher for males than for females (male/female rate was $2.0 \%$ or less) in reports including 100 cases or more. For example, Collins [70], Bonduelle et al. [71], Boman and Meurman [72], Erbslöh et al. [73], Kondo [74], and Haberlandt [75] reported that the male/female rate ratio was 1.1, 1.2, 1.3, 1.5, 1.5, 2.0, respectively. According to my data, there was no statistically significant difference in the NM, ATA, or ACR of myelinated axons between the female and male femoral and tibial nerve specimens $(P<0.05$; Table 1). These findings may partly explain why there is little significant sex difference in the incidence of motor neuropathy. Therefore, sex difference in the incidence of motor neuropathy is considered to be caused not only due to the morphology of the motor neurons, but also because of sex hormones and other factors.

\subsection{Greater splanchnic and lesser splanchnic nerve}

Shinoda analyzed data on adult autonomic neuropathy in past reports and mentioned that the vulnerability of male autonomic neurons was higher than that of females [69]. Hogarth and coworkers' study demonstrated that females have a lower central sympathetic nerve activity to the periphery, the mechanism of which involves a greater baroreceptor reflex inhibitory effect on this activity in females than in males [76]. These findings could have implications regarding the lower number of cardiovascular events observed in females than in males. Muneta et al. reported that the activation of the sex center regulating gonadotropin secretion may be a causative factor in the baroreflex impairment in females [77]. They also mentioned that changes in blood pressure in females are more sensitive to mental stress, but less so to isometric stress than those of males. These findings suggest that ovarian dysfunction is another important factor influencing the baroreflex function in addition to aging and blood pressure, and that the baroreflex impairment in females characterizes the sex difference in the pathophysiology of essential hypertension. Hinojosa-Laborde et al. reported that clear evidence exists for differences in the regulation of the sympatho-adrenal nervous system between males and females [78]. At each level of neural control examined in their review, females were able to limit the activation or enhance the inhibition of the sympathetic nervous system (SNS) more effectively than males during at least part of the oestral/menstrual cycle. These observations suggest that the ability of females to more tightly control the SNS and, subsequently, arterial pressure may serve as a mechanism whereby sex hormones protect females against hypertension. Here, there was no statistically significant difference in the NM, ATA, or ACR of myelinated axons between the female and 
male specimens of the greater splanchnic and lesser splanchnic nerve $(P<0.05$; Table 1$)$. These findings do not explain why there is a significant sex difference in the incidence of autonomic dysfunction. Therefore, the morphology of autonomic neurons may not be the cause of sex differences in the incidence of autonomic dysfunction and other factors such as sex hormones may be the cause.

\section{Author details}

Hiroshi Moriyama

Showa University School of Medicine, Japan

\section{Acknowledgement}

We thank Ms. Ikuko Moriyama for assistance in preparing the manuscript. This work was supported by a Grant-in-aid for Scientific Research B14370007 from the Ministry of Education, Culture, Sports, Science and Technology of Japan.

\section{References}

[1] Moriyama H, Amano K, Itoh M, Shimada K, Otsuka N (2007) Morphometric aspects of peripheral nerves in adults and the elderly. J Peripher Nerv Syst 12:205-209

[2] Eckel HE, Sittel C, Walger M, Sprinzl G, Koebke J (1993) Plastination: a new approach to morphological research and instruction with excised larynges. Ann Otol Rhinol Laryngol 102:660-665

[3] Fukuda M, Morimoto T, Suzuki Y, Kida K, Ohnishi A (2000) Congenital neuropathy with the absence of large myelinated fibers. Pediatr Neurol 23:349-351

[4] Griffn JW, Höke A (2005) The control of axonal caliber. In: Dyck PJ, Thomas PK (eds) Peripheral Neuropathy, 4th edn, vol 1. Elsevier Saunders, Philadelphia, pp 433-446

[5] Korinthenberg R, Sauer M, Ketelsen UP, Hanemann CO, Stoll G, Graf M, Baborie A, Volk B, Wirth B, Rudnik-Schoneborn S, Zerres K (1997) Congenital axonal neuropathy caused by deletions in the spinal muscular atrophy region. Ann Neurol 42:364-368

[6] Lin KP, Soong BW (2002) Peripheral neuropathy of Machado-Joseph disease in Taiwan: a morphometric and genetic study. Eur Neurol 48:210-217

[7] Moriyama H, Shimada K, Goto N (1995) Morphometric analysis of neurons in ganglia: geniculate, submandibular, cervical spinal and superior cervical. Okajimas Folia Anat Jpn 72:185-190

[8] Cabrejas L, Hurtado-Ceña FJ, Tejedor J (2009) Predictive factors of surgical outcome in oculomotor nerve palsy. J AAPOS 13:481-484

[9] Ohguro H, Takeda M, Nakagawa T (1986) Acquired oculomotor nerve palsy: A review of 74 cases. Neuro-ophthalmol Jpn 3:263-266 (Japanese)

[10] Katusic S, Beard CM, Bergstralh E, Kurland LT (1990) lncidence and clinical features of trigeminal neuralgia, Rochester, Minnesota, 1945-1984. Ann Neurol 27:89-95 
[11] Ashkenazi A, Levin M (2004) Three common neuralgias. How to manage trigeminal, occipital, and postherpetic pain. Postgrad Med 116:16-32

[12] Love S, Coakham HB (2001) Trigeminal neuralgia: pathology and pathogenesis [published correction appears in Brain. 2002;125:687]. Brain 124:2347-2360

[13] Apfelbaum R (1988) Surgical management of disorders of the lower cranial nerves. In: Schmideck H, Sweet W, (eds) Operative neurosurgical techniques. 2nd edn, Grune \& Stratton, New York, pp. 1097-1109

[14] Wilkins RH (1988) Surgical therapy of neuralgia: Vascular decompression procedures. Semin Neurol 8:280-285

[15] Jannetta PJ (1990) Cranial rhizopathies. In: Youmans JR (ed) Neurological surgery. 3rd edn, WB Saunders, Philadelphia, pp. 4169-4182

[16] Barker FG II, Jannetta PJ, Bissonette DJ, Larkins MV, Jho HD (1996) The long-term outcome of microvascular decompression for trigeminal neuralgia. $\mathrm{N}$ Engl J Med 334:1077-83

[17] Pogrel MA, Thamby S (2000) Permanent nerve involvement resulting from inferior alveolar nerve blocks. J Am Dent Assoc 131:901-907

[18] Lambrianidis T, Molyvdas J (1987) Paresthesia of the inferior alveolar nerve caused by periodontal-endodontic pathosis. Oral Surg Oral Med Oral Pathol 63:90-92

[19] Pogrel MA, Bryan J, Regezi J (1995) Nerve damage associated with inferior alveolar nerve blocks. J Am Dent Assoc 126:1150-1155

[20] Giuliani M, Lajolo C, Deli G, Silveri C (2001) Inferior alveolar nerve paresthesia caused by endodontic pathosis: A case report and review of the literature. Oral Surg Oral Med Oral Pathol Oral Radiol Endod 92:670-674

[21] Panula K, Finne K, Oikarinen K (2001) Incidence of complications and problems related to orthognathic surgery: A review of 655 patients. J Oral Maxillofac Surg 59:1128-1136

[22] Blanas N, Kienle F, Sàndor GKB (2002) Injury to the Inferior alveolar nerve due to thermoplastic gutta percha. J Oral Maxillofac Surg 60:574-576

[23] Kraut RA, Chahal O (2002) Management of patients with trigeminal nerve injuries after mandibular implant placement. J Am Dent Assoc 133:1351-1354

[24] Teerijoki-Oksa T, Jääskeläinen S, Forssell K, Virtanen A, Forssell H (2003) An evaluation of clinical and electrophysiology tests in nerve injury diagnosis after mandibular sagittal split osteotomy. Int J Oral Maxillofac Surg 32:15-23

[25] Haas DA, Lennon D (1995) A 21 year retrospective study of reports of paresthesia following local anesthetic administration. J Can Dent Assoc 61:319- 320, 323-326, 329330

[26] Kipp DP, Goldstein BH, Weiss WW Jr (1980) Dysesthesia after mandibular third molar surgery: A retrospective study and analysis of 1,377 surgical procedures. J Am Dent Assoc 100:185-192

[27] Harn SD, Durham TM (1990) Incidence of lingual nerve trauma and postinjection complications in conventional mandibular block anesthesia. J Am Dent Assoc 121:519523

[28] Howe GL, Poyton HG (1960) Prevention of damage to the inferior dental nerve during the extraction of mandibular third molars. Br Dent J 109:355-363 
[29] Queral-Godoy E, Valmaseda-Castellon E, Berini-Aytes L, Gay-Escoda C (2005) Incidence and evolution of inferior alveolar nerve lesions following lower third molar extraction. Oral Surg Oral Med Oral Pathol Oral Radiol Endod 99:259-264

[30] Wagner R, DeLeo JA, Coombs DW, Myers RR (1995) Gender differences in autotomy following sciatic cryoneurolysis in the rat. Physiol Behav 58:37-41

[31] Coyle DE, Sehlhorst CS, Mascari C (1995) Female rats are more susceptible to the development of neuropathic pain using the partial sciatic nerve ligation (PSNL) model. Neurosci Lett 186:135-138

[32] Heasman PA, Beynon ADG (1987) Myelinated axon counts of human inferior alveolar nerves. J Anat 151:51-56

[33] Patel SV, Mutyala S, Leske DA, Hodge DO, Holmes JM. (2004) Incidence, associations, and evaluation of sixth nerve palsy using a population-based method. Ophthalmology. 111:369-75

[34] Campbell KE, Brundage JF (2002) Effects of climate, latitude, and season on the incidence of Bell's palsy in the US armed forces, October 1997 to September 1999. Am J Epidemiol 156:32-39

[35] Monini S, Lazzarino AI, Iacolucci C, Buffoni A, Barbara M (2010) Epidemiology of Bell's palsy in an Italian Health District: incidence and case-control study. Acta Otorhinolaryngol Ital 30:198-204

[36] Tiemstra JD, Khatkhate N (2007) Bell's palsy: diagnosis and management. Am Fam Physician 76:997-1002

[37] Hullar TE, Minor LB, Zee DS (2005) Evaluation of the patient with dizziness. In: Cummings CW (ed) Cummings otolaryngology head \& neck surgery, 4th edn, vol 4. Elsevier Mosby, Philadelphia, pp 3160-3198

[38] Lempert T, Neuhauser H (2009) Epidemiology of vertigo, migraine and vestibular migraine. J Neurol 256:333-338

[39] Neuhauser HK, von Brevern M, Radtke A, Lezius F, Feldmann M, Ziese T, Lempert T (2005) Epidemiology of vestibular vertigo: a neurotologic survey of the general population. Neurology 65:898-904

[40] Yin M, Ishikawa K, Wong WH, Shibata Y (2009) A clinical epidemiological study in 2169 patients with vertigo. Auris Nasus Larynx 36:30-5

[41] Wladislavosky-Waserman P, Facer GW, Mokri B, Kurland LT (1984) Menière's disease: a 30-year epidemiologic and clinical study in Rochester, Mn, 1951-1980. Laryngoscope 94:1098-1102

[42] Havia M, Kentala E, Pyykkö I (2005) Prevalence of Menie're's disease in general population of Southern Finland. Otolaryngol Head Neck Surg 133:762-768

[43] Davis B (1987) The incidence of tinnitus. In: Slater R, Terry M (eds) Tinnitus: a guide for sufferers and professionals. Croom Helm, Beckenham, Kent, pp 88-98

[44] Graham JT (1965) Relation of tinnitus to age. Acta Otolaryngol 59(s202):24-26

[45] Coles RRA (1984) Epidemiology of tinnitus: demographic and clinical features. J Laryngol Otology (Suppl 9):195-202

[46] Møller MB, Møller AR, Jannetta PJ, Jho HD (1993) Vascular decompression surgery for severe tinnitus: Selection criteria and results. Laryngoscope 103:421-427 
[47] Kacker SK (1997) Hearing impairment in the aged. lndian J Med Res 106:333-339

[48] Hinchcliffe R, Jones WI (1968) Hearing levels of a suburban Jamaican population. Int J Audiol 7:239-258

[49] Bunch CC, Raiford TS (1931) Race and sex variations in auditory acuity. Arch Otolaryngol 13:423-434

[50] Berger EH, Royster LH, Thomas WG (1977) Hearing levels of nonindustrial exposed subjects. J Occup Med 19:664-670

[51] Starr A, Picton TW, Sininger Y, Hood LJ, Berlin CI (1996) Auditory neuropathy. Brain 119:741-753

[52] Nakashima T (2001) Sudden deafness. In: Nomura Y, Komatsuzaki A, Honjyo I (eds) Clinical textbooks of the ear, nose and throat regions 21, No. 5. Nakayama Shoten Co. Ltd., Tokyo, pp 259-269 (Japanese)

[53] Araújo CG, Nobrega AC, Castro CL. (1989) Vagal activity: effect of age, sex and physical activity pattern. Braz J Med Biol Res 22:909-211

[54] Bruyn GW (1983) Glossopharyngeal neuralgia. Cephalalgia 3:143-157

[55] Kandan SR, Khan S, Jeyaretna DS, Lhatoo S, Patel NK, Coakham HB (2010) Neuralgia of the glossopharyngeal and vagal nerves: long-term outcome following surgical treatment and literature review. Br J Neurosurg 24:441-446

[56] Crue BL, Todd EM (1968) Vagal neuralgia. In: Vinken PJ, Bruyn GW (eds) Headaches and cranial neuralgias. North-Holland Pub. Co., Amsterdam, pp 362-367

[57] Rushton JG, Stevens JC, Miller RH (1981) Glossopharyngeal (vagoglossopharyngeal) neuralgia: a study of 217 cases. Arch Neurol 38:201-205

[58] Khasar SG, Isenberg WM, Miao FJ, Gear RW, Green PG, Levine JD (2001) Gender and gonadal hormone effects on vagal modulation of tonic nociception. J Pain 2:91-100

[59] Titche LL (1976) Causes of recurrent laryngeal nerve paralysis. Arch Otolaryngol 102:259-261

[60] Parnell FW, Brandenburg JH (1970) Vocal cord paralysis: A review of 100 cases. Laryngoscope 80:1036-1045.

[61] Nozoe I, Hirano M, Shin T, Maeyama T (1972) Recurrent laryngeal nerve palsy: A clinical study 400 cases. Otologia Fukuoka 18:411-417

[62] Hojyo M, Nishiyama H (1972) The statistical observation of recurrent laryngeal nerve palsy. Jpn J Natl Med Serv 26:597-601

[63] Yanohara K, Hisa Y, Suzuki Y, Mizuta Y, Matsui T, Sato F, Mizukoshi O (1978) Clinical aspect of recurrent laryngeal nerve palsy. Pract Otol Kyoto 71:1201-1207

[64] Yamada M, Hirano M, Ohkubo H (1983) Recurrent laryngeal nerve paralysis: A 10-year review of 564 patients. Auris Nasus Larynx 10(Suppl):S1-15

[65] Ishikawa T (1977) Clinical study of unilateral vocal cord paralysis: Level differences between the vocal cords. Pract Otol Kyoto 70:453-461

[66] Work WP (1941) paralysis and paresis of the vocal cords: A statistical review. Arch Otolaryngol 34:267-280

[67] Huppler EG, Schmidt HW, Devine D (1955) Causes of vocal-cord paralysis. Proc Staff Meet Mayo Clin 30:518-521 
[68] Hirose H, Sawashima M, Yoshioka H (1981) Clinical observations on 750 cases of laryngeal palsy. Ann Bull RILP 15:173-180

[69] Shinoda K (1998) Sex difference in adult neuropathy. Sex Difference and Similarity 4:3444 (Japanese)

[70] Collins J (1903) Amyotrophic lateral sclerosis. Am J Med Sci 125:939-967

[71] Bonduelle M, Bouygues P, Lormeau G, Keller J (1970) Clinical and developmental study of 125 cases of amyotrophic lateral sclerosis: Nosographic limitations and morbid associations. Presse Med 78:827-832 (French)

[72] Boman K, Meurman T (1967) Prognosis of amyotrophic lateral sclerosis. Acta Neurol Scand 43:489-498

[73] Erbslöh F, Kunze K, Recke B, Abel M (1968) The myatrophic lateral sclerosis: Clinical, electromyographic and biopsy-histological studies on 112 patients. Dtsch Med Wochenschr 93:1131-41 (German)

[74] Kondo K (1975) Clinical variability of motor neuron disease. Neurological Medicine 2:11-16 (Japanese)

[75] Haberlandt WF (ed) (1964) Amyotrophische Lateralsklerose Klinisch - pathologische und genetisch-demographische Studie. Gustav Fischer Verlag, Stuttgart, pp. 1-185

[76] Hogarth AJ, Mackintosh AF, Mary DA (2007) Gender-related differences in the sympathetic vasoconstrictor drive of normal subjects. Clin Sci (Lond) 112:353-61.

[77] Muneta S, Murakami E, Hiwada K (1994) Gender difference in blood pressure regulation in essential hypertension. Hypertens Res 17:71-78

[78] Hinojosa-Laborde C, Chapa I, Lange D, Haywood JR (1999) Gender differences in sympathetic nervous system regulation. Clin Exp Pharmacol Physiol 26:122-6 